\title{
Math 1, retinoic acid, and TNF- $\alpha$ synergistically promote the differentiation of mucous cells in mouse middle ear epithelial cells in vitro
}

\author{
Yoshihisa Nakamura' ${ }^{1}$, Masahiro Komori' ${ }^{1}$ Kazuhiro Yamakawa' ${ }^{1}$ Yuki Hamajima' ${ }^{1}$, Motohiko Suzuki², Youngki Kim³ \\ and Jizhen Lin ${ }^{1}$
}

BACKGROUND: A key issue in otitis media (OM) is mucous cell metaplasia in the middle ear mucosa, a condition for hyperproduction of mucus in the middle ear mucosa and development of chronic OM. However, little is known about the driving force for the differentiation of mucous cells in $\mathrm{OM}$.

METHODS: Mouse middle ear epithelial cells (mMEECs) were used in this study to test whether Math1, a critical transcription factor for the development of mucous cells in the intestine, synergizes with inflammatory cytokines (tumor necrosis factor- $\alpha($ TNF- $\alpha)$ ) and other epithelial differentiation factors (retinoid acid (RA)) to induce the differentiation of mMEECs into mucus-like cells in vitro. Simultaneously, Math1 was transduced into the middle ear mucosa in order to observe whether it induces mucous cell hyperplasia in vivo.

RESULTS: Math1 significantly increased the mucus cell numbers in the middle ear mucosa of mice. Math1, in the presence of TNF- $\alpha$ and epithelial differentiation factor RA, synergistically promoted the differentiation of mMEECs into mucus-like cells through upregulation of mucins and their chaperones: trefoil factors in vitro. RA treatment for $12 \mathrm{~h}$ activated Math1, although RA alone had very limited effects on mucus-like cell differentiation.

CONCLUSION: Math 1 plays a critical role in the pathogenesis of OM by induction of mucous cell differentiation in the presence of TNF- $\alpha$ and RA.

U nder normal conditions, few mucous cells exist in the middle ear mucosa of humans and rodents, and they are mainly distributed in the orifice of the Eustachian tube, promontory area, and inferior tympanium (the so-called "ciliated tract"). Under pathological conditions, mucous cells are dramatically increased (1-7), with abundant production of mucins $(2,8)$ and mucin chaperones: trefoil factors (TFFs) (9). Upregulation of mucins and mucin chaperones is a biological basis for mucous cell metaplasia (MCM), a predisposition for chronic otitis media $(\mathrm{OM})$.
It is known that proinflammatory cytokines such as tumor necrosis factor- $\alpha$ (TNF- $\alpha$ ) are involved in the development of MCM in animal models (10). However, little is known about the additional factors needed for the differentiation of mucous cells. Math1 (Atoh1, atonal homolog 1) knockout mice developed no mucous cell lineage in the intestine, suggesting that Math1 is a candidate involved in the development of MCM in OM. Because the Math1 knockout mouse model is embryonic lethal (11) and not available for MCM, we sought to investigate this issue using in vitro "knock-in" techniques in mouse middle ear epithelial cells (mMEECs).

A classic pathway for MCM is middle ear infection. Inflammatory cells produce cytokines, and cytokines, in turn, stimulate the differentiation of mucous cells $(2,10)$. A number of cytokines generated from inflammatory cells upregulate the expression of mucins and induce MCM. These cytokines include TNF- $\alpha$ (10,12-14), interleukin (IL)-4 (15), IL-10 (16), IL-8 (17), IL-9 (18), and IL-13 (19-21). They are either proinflammatory cytokines or lymphocyte (especially the T-helper 2 subset)-derived cytokines.

We hypothesized in this study that Math1, together with TNF- $\alpha$ and retinoid acid (RA), plays an important role in the differentiation of mucous cells in the middle ear. As expected, transfection of mMEECs with Math1 regulated the expression of mucins and TFFs in the presence of TNF- $\alpha$ and RA.

\section{RESULTS}

Math1 Transfection Induces MCM in the Middle Ear Mucosa of Mice

To study the importance of the Math1 gene in differentiation of mucous cells, transfection of Math1 in the middle ear was performed in the 10 bullae of five mice. It was found that mucous cell numbers were increased in Math1-transfected middle ear mucosa (Figure 1a) as compared with empty vector (ev)-transfected middle ear mucosa (Figure 1b). Statistically, Alcian blue-periodic acid Schiff (AB-PAS)-positive cells were

'Department of Otolaryngology, University of Minnesota School of Medicine, Minneapolis, Minnesota; ${ }^{2}$ Department of Otolaryngology, Nagoya City University School of Medicine, Nagoya, Japan; ${ }^{3}$ Department of Pediatrics, University of Minnesota School of Medicine, Minneapolis, Minnesota. Correspondence: Jizhen Lin (linxx004@umn.edu) 

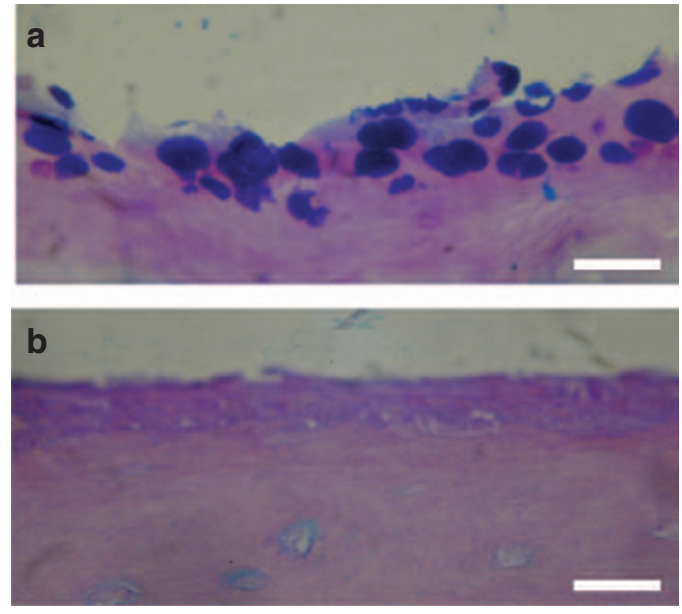

C

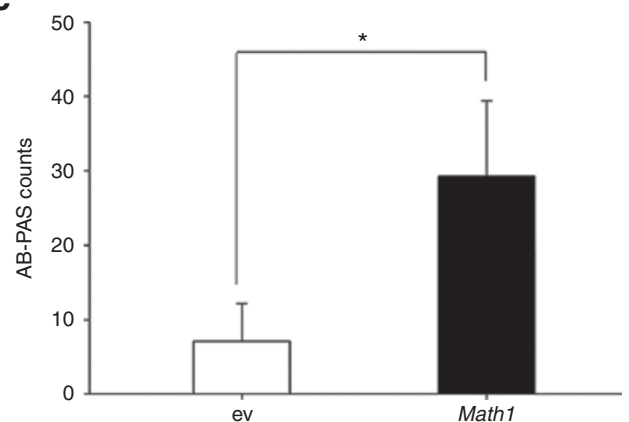

Figure 1. Math1 transfection increases mucous cell numbers in the middle ear mucosa of mice. (a) Math1 transfection had more AB-PAS-positive cells in the mouse middle ear mucosa than (b) empty vector transfection. (c) Statistical analysis showed that Math1 significantly increased the AB-PAS cell counts in the middle ear mucosa of five mice. ${ }^{*} P<0.01(n=5)$; bar $=10 \mu \mathrm{m}$. AB-PAS, Alcian blue-periodic acid Schiff.

significantly higher in the bullae transfected with Math1 than in those transfected with ev (Figure 1c).

\section{Math1 Transfection Alone In Vitro Does Not Induce Mucous Cell} Differentiation

To investigate the role of Math1, cultured mMEECs were stably transfected with Math1 or ev. After incubation with G418 for more than 3 mo, surviving cells were submitted for selection of green fluorescent protein-positive cells. Math1 was weakly expressed in ev-transfected cells. Math1 transfection successfully increased the expression of Math 1 by reverse-transcription PCR (RT-PCR), fluorescence-activated cell sorting (FACS), and immunohistochemistry (see Supplementary Figure S1 online), suggestive of efficient transfection of Math1 in cultured mMEECs. To study whether Math1 is involved in the development of mucous cells, Math1 and ev stably transfected cells were incubated with various factors for $14 \mathrm{~d}$ and then without these factors for $2 \mathrm{~d}$ before harvesting for evaluations. Microarray data confirmed that Math1 alone increased the mRNA of mucins (including Muc1, Muc2, Muc4, and Muc5ac, but not Muc3 or Muc10) and mucin chaperones (TFF1 and TFF2, but not TFF3) as compared with ev (Figure 2). However, Math1 transfection alone did not significantly increase the AB-PAS-positive cell numbers (Figure 3a), nor the expression of Muc2 protein in the cells as assessed by immunohistochemistry (Figure 3b). Math 1 increased the percentage of Muc2- and TFF3-positive cells when used together with TNF- $\alpha$ and RA in comparison with ev as assessed by FACS (Figure 3c).

RA+TNF- $\alpha+$ Math1 Synergistically Induces the Formation of Mucous Granules in Cultured mMEECs

Under inflammatory conditions, various cytokines and factors exist in the middle ear. To study whether they synergize in triggering the differentiation of mucous cells, mMEEC cell cultures were incubated with and without inflammatory cytokines and factors for $14 \mathrm{~d}$, then without any factors for $2 \mathrm{~d}$ to allow them to differentiate. It was found that the combination of TNF- $\alpha+\mathrm{RA}$ was able to synergistically increase the number of AB-PAS-positive cells, whereas RA and TNF- $\alpha$ alone were unable to do so (see Supplementary Figure S2 online). To study whether Math1 is involved in the differentiation of mucous cells under inflammatory conditions, Math1 and ev stably transfected cells were incubated with TNF- $\alpha+$ RA for 14 $\mathrm{d}$ and then without TNF- $\alpha+\mathrm{RA}$ for $2 \mathrm{~d}$. It was found that TNF$\alpha+\mathrm{RA}+$ Math 1 had significantly higher numbers of AB-PASpositive cells as compared with TNF- $\alpha+\mathrm{RA}+\mathrm{ev}$ (Figure 3a). Immunohistochemistry demonstrated that TNF- $\alpha+\mathrm{RA}+$ Math 1 obviously increased the expression of both Muc2 and TFF3 in cells as compared with controls (ev, Math1, RA+Math1, and TNF- $\alpha+$ Math 1 ; Figure $3 b$ ). It has been noted that translocation of Math1 protein to the nucleus was observed in the presence of RA and/or TNF- $\alpha$ (namely, RMath1, TMath1, or TRMath1). Math1 transfection alone did not produce sufficient Math1 protein in the nucleus (Math1), suggesting that TNF- $\alpha$ and/or RA activate Math1 in the nuclei. This explains why the TNF$\alpha+\mathrm{RA}+$ Math 1 cocktail is essential for the induction of mucous cell differentiation. FACS showed that Math1 transfectants had an increased percentage of both Muc2- and TFF3-positive cells as compared with ev transfectants in the presence of TNF$\alpha+R A$ (Figure 3c), i.e., TNF- $\alpha+R A+M a t h 1$ increased the percentage of both Muc2- and TFF3-positive cells. It is noted that Muc2-positive cells were also TFF3-positive cells (Figure 3c).

\section{RA Activates Math1 in mMEECs}

To study whether RA activates Math1, cells were incubated with various factors (with and without RA, TNF- $\alpha$, and TNF- $\alpha+$ RA for 2-48h) and harvested for RT-PCR, immunohistochemistry, and FACS. It was demonstrated that RA treatment for 12-24h increased the expression of Math1 mRNA transcripts by RT-PCR (Figure 4a). PCR negative controls were all negative. FACS demonstrated that RA, alone or in combination with TNF- $\alpha$, increased the percentage of Math1-positive cells (Figure $4 \mathrm{~b}$ ). Immunohistochemistry demonstrated that RA increased the expression of the Math1 protein in a time-dependent manner and translocated it into the nuclei (Figure 4c).

\section{Multiple Signaling Pathways Are Involved in Mucous Cell Differentiation by TNF- $\alpha+\mathrm{RA}+$ Math 1}

It remains unclear how RA, TNF- $\alpha$, and Math1 alone and in combination affect the differentiation of mucous cells. To 
a
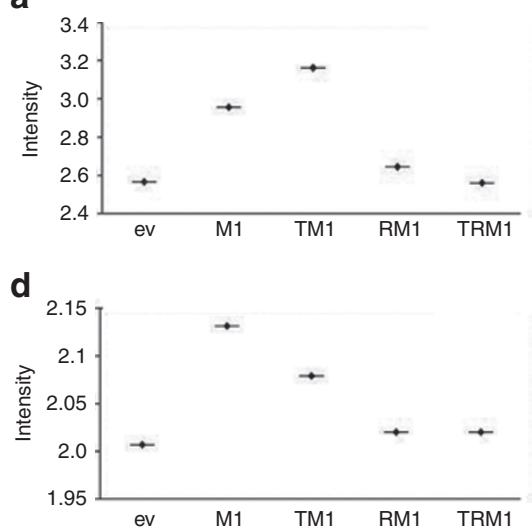

g

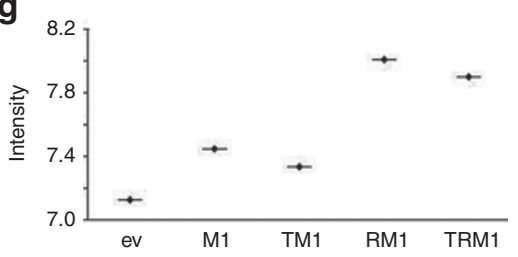

j

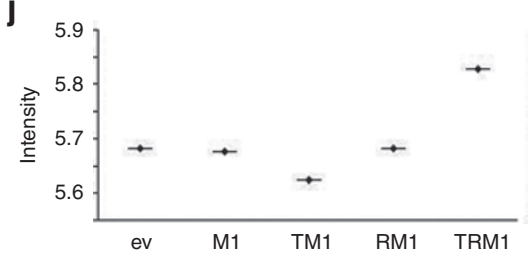

b

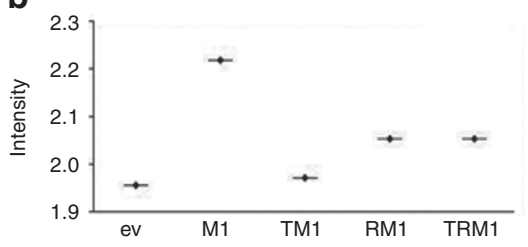

e

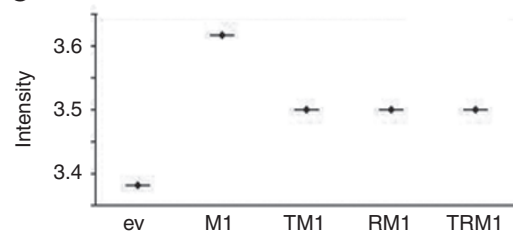

h

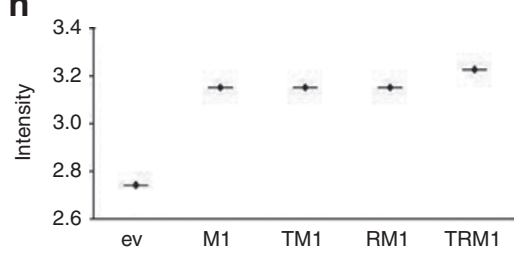

$\mathbf{k}$

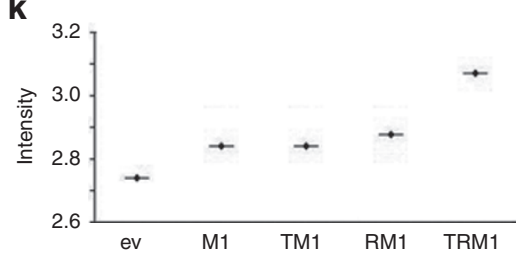

C

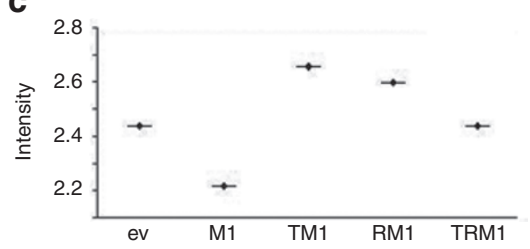

f

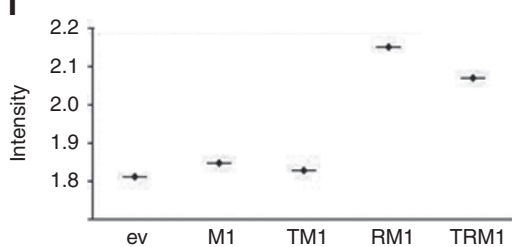

i

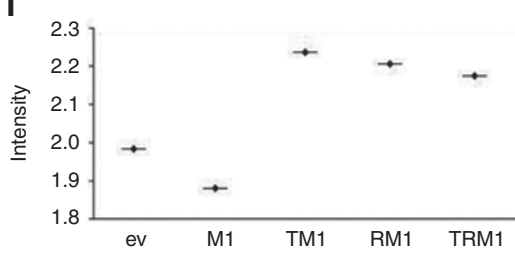

Figure 2. Math1 regulates the expression of mucous cell markers at the mRNA level in cultured mMEECs. Microarray data confirmed the upregulation of mucins (a) Muc1, (b) Muc2, (d) Muc4, and (e) Muc5ac, but not (c) Muc3 or (f) Muc10, and mucin chaperones (g) TFF1 and (h) TFF2, but not (i) TFF3, at the mRNA level. TNF- $\alpha+R A+$ Math1 (TRM1) increased the expression of (g) TFF1, (h) TFF2, (i) TFF3, (j) EGFR, and (k) Akt at the mRNA level. EGFR, epidermal growth factor receptor; ev, empty vector; mMEEC, mouse middle ear epithelial cell; RA, retinoid acid; RM1, RA+Math1; TFF, trefoil factor; TM1, TNF$\alpha+$ Math $1 ;$ TNF- $\alpha$, tumor necrosis factor- $\alpha ;$ TRM1, TNF- $\alpha+R A+$ Math1.

probe the likely signaling pathways for mucous cell differentiation, we evaluated the effects of various chemical inhibitors on mucous granule formation. All the inhibitors except for JAK1 significantly inhibited TNF- $\alpha+\mathrm{RA}+$ Math1-induced mucous granulation in cultured mMEECs (Figure 5a). Immunohistochemistry demonstrated that in comparison with dimethyl sulfoxide, PD98059, SB203580, LY294002, AG1478, and SP600125 reduced the expression of the mucous cell marker TFF3 in Math1 stably transfected and TNF- $\alpha+$ RAtreated cells (Figure $5 \mathbf{b}$ ). Taken together, the data show that multiple pathways are involved in the differentiation of mucous cells induced by TNF- $\alpha+\mathrm{RA}+$ Math 1 .

\section{DISCUSSION}

In this study, we demonstrated for the first time that mMEECs have the potential to differentiate into mucous-like cells under certain circumstances. The inductive factors are a triad of master regulators for MCM: Math1, TNF- $\alpha$, and RA. There is an expression baseline of Math1 in mMEECs. RA or retinoids are also available in the middle ear mucosa. Under normal conditions, these mMEECs become epithelial cells instead of mucous cells. But under inflammatory conditions, TNF- $\alpha$ and other cytokines are induced and released. This results in the synergy of the following three important factors, Math1, TNF- $\alpha$, and RA, on the middle ear epithelial cells. Math1 alone has some effects on the expression of mucous cell markers such as mucins and TFFs at the mRNA level (Figure 2) but is limited at the protein level (Figure 3). Math1, TNF- $\alpha$, and RA synergistically regulate mucins and mucin chaperones (TFFs) at both the mRNA and protein levels. This indicates that MCM requires converged signaling pathways from multiple factors (Figure 6). Mucous granules are formed when Math1, RA, and TNF- $\alpha$ reach a certain level, i.e., the so-called threshold for MCM. These mucous granules are AB-PAS positive, and cells containing abundant mucous granules are mucous cells by nature. Rather, these cells in vitro are not mature mucous cells but are en route to becoming mucous cells.

How do TNF- $\alpha$, RA, and Math 1 make this happen? First, each of these factors plays a role in the regulation of mucins, hallmark proteins for mucous cells. These upregulated mucins are multiple: soluble mucins such as Muc2, Muc5ac, and Muc5b, and membrane-bound mucins such as Mucl and Muc4. Math1 has potential effects on the expression of Muc1, Muc2, Muc4, and Muc5ac but not on Muc3 or Muc10, based on the microarray data (Figure 2), and in fact, Math1 transfection increases the expression of Muc2 protein in the presence of RA+TNF- $\alpha$ 
a

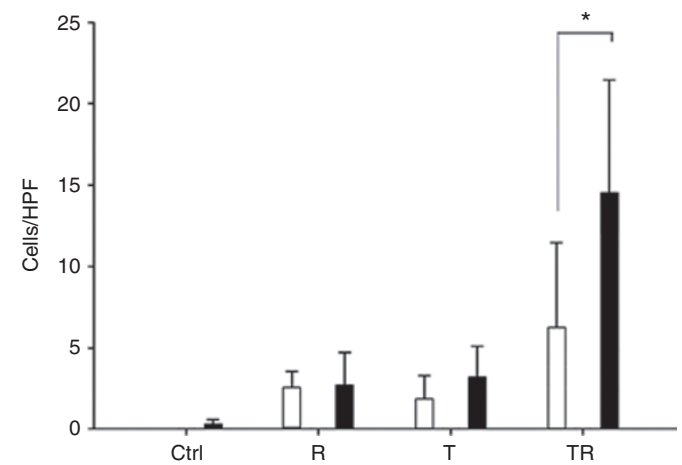

C

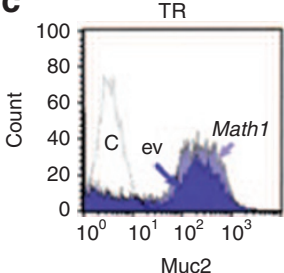

TR

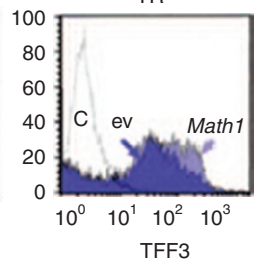

TR

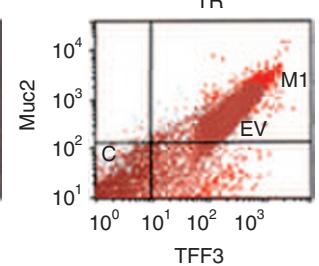

b

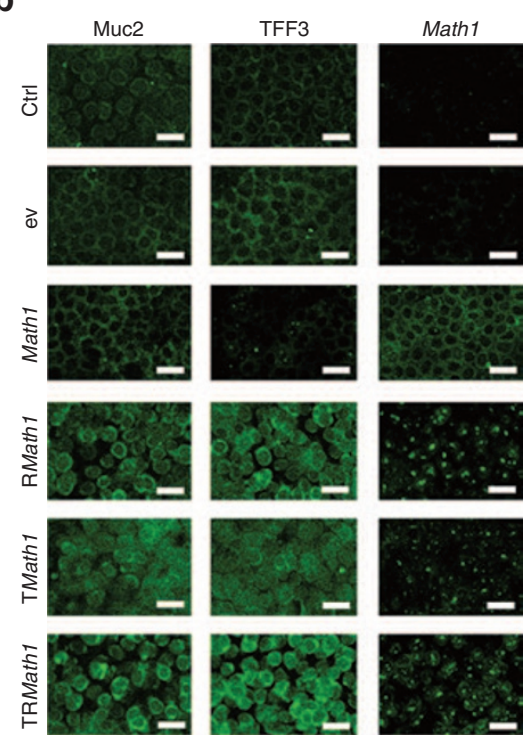

Figure 3. TNF- $\alpha+R A+M a t h 1$ synergistically increased mucous granules (AB-PAS-positive cells) in cultured cells. Cells were treated with various factors for $14 \mathrm{~d}$ and then without these factors for $2 \mathrm{~d}$. RA and TNF- $\alpha$ alone induced few AB-PAS-positive cells, and Math 1 transfection alone did not significantly increase the AB-PAS-positive cells as compared with ev (a, AB-PAS staining). However, TNF- $\alpha+R A+M a t h 1$ significantly increased the percentage of AB-PAS-positive cells as compared with TNF- $\alpha+R A$ ( $\mathbf{a},{ }^{*} P<0.05, n=6$ ). empty bar, ev; solid bar, Math1; R, RA; T, TNF- $\alpha$; TR, TNF- $\alpha+R A$. (b) Immunohistochemistry showed that the TNF- $\alpha+R A+$ Math 1 cocktail obviously increased the expression of both Muc2 and TFF3. Bar $=10 \mu m$. FACS verified that Math 1 transfection increased the percentage of positive cells for Muc 2 and TFF3 as compared with ev in the presence of RA and TNF- $\alpha$, and (c) cells positive for Muc2 were also positive for TFF3. AB-PAS, Alcian blue-periodic acid Schiff; Ctrl, control (untransfected cells); ev, empty vector; FACS, fluorescence-activated cell sorting; HPF, high-power field; RA, retinoid acid; RMath1, RA+Math1; TFF, trefoil factor; TNF- $\alpha$, tumor necrosis factor- $\alpha$; TMath1, TNF- $\alpha+$ Math 1; TRMath1, TNF- $\alpha+$ RA+Math1.

(Figure 3c). Consistent with this, Leow et al. (22) reported that Math1 is related to MUC2 mucin upregulation. Sekine et al. (23) reported that overexpression of Math1 in gastric cancer cells enhanced MUC5AC mRNA and knockdown of Math1 by RNA interference decreased MUC5AC gene expression. In our previous studies, TNF- $\alpha$ stimulated the expression of mucins (Muc2) in the rat middle ear mucosa and promoted the differentiation of mucous cells (12). In line with this, we found that TNF- $\alpha$, in in vitro conditions, regulates the expression of Muc2 (Figure $3 \mathbf{b}$ ) and slightly stimulates the differentiation of mucous cells. In terms of RA, it has been reported that the expressions of MUC2, MUC5AC, and MUC5B are dependent on the presence of RA because these mucin mRNA transcripts were not detected in the RA-deficient cultures (24). Our current study demonstrated that RA treatment induces the expression of Muc2 as assessed by immunohistochemistry (Figure 3b). Second, in the presence of Math1, TNF- $\alpha$, and/or RA regulate the expression of mucin (Muc2) and the mucin chaperone TFF3 (Figure 3b). TFFs are essential for packing mucins into mucus granules (9), which stain positive for AB-PAS. Neither mucins nor TFFs alone make any mucous granules, so the upregulation of both mucins and TFFs at the same time is a prerequisite for the formation of mucous granules and differentiation of cells into mucous-like cells. Math1 transfection had increased the expression of Math 1 in the cytosol. However, these upregulated proteins were not translocated to the nuclei without the presence of TNF- $\alpha$ and/or RA (Figure $3 b$ ). This may explain why Math 1 transfection alone has a limited or no effect on the expression of TFF3 (Figure 2). Math1 is thought to synergize the expression of TFF3 because Math1 transfection strengthened the effects of TNF- $\alpha+$ RA on TFF3 expression (Figure 3c). The pathway to TFF3 is still poorly understood. It has been reported that the PI3-K/Akt pathway links to TFF3 expression in TH29 cells under confluence (25). Consistent with this, an Akt-specific inhibitor, LY294002, inhibited the expression of TFF3 + Math 1 by TNF- $\alpha+\mathrm{RA}+$ Math1 (Figure $5 \mathrm{~b}$ ). TFFs are known to stimulate their own release as well as that of other family members, and this auto- or cross-induction of TFFs requires indirect activation of the epidermal growth factor receptor (EGFR) (26). This may be one of reasons why the EGFR tyrosine kinase inhibitor AG1478 inhibited the expression of TFF3 by TNF- $\alpha+$ RA (Figure $5 b$ ). Our microarray data showed the remarkable upregulation of Akt (AF124142), and EGFR was observed in TNF- $\alpha+$ RA+Math1-treated cells (Figure 2). These signaling pathways induced by the combination of factors may explain the synergistic effects of TNF- $\alpha+\mathrm{RA}+$ Math 1 on TFF3 expression or mucous cell differentiation.

RA has been shown to regulate epithelial cell differentiation related to mucin gene regulation in rabbit tracheal-epithelial cells in vitro (27) and restore squamous cells to a mucous cell phenotype when cells are deprived of retinoids (28). In this study, we demonstrated that RA mainly regulates the expression and activation of Math1, which further potentiates the expression of both mucins and mucin chaperones. The upregulation of mucins and mucin chaperones to a certain level may trigger the differentiation of epithelial cells to mucous cells. Although either TNF- $\alpha$ or RA alone is capable of upregulating 
a
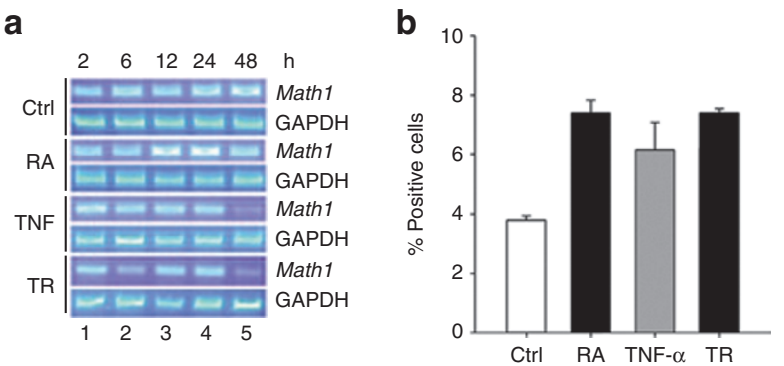

C

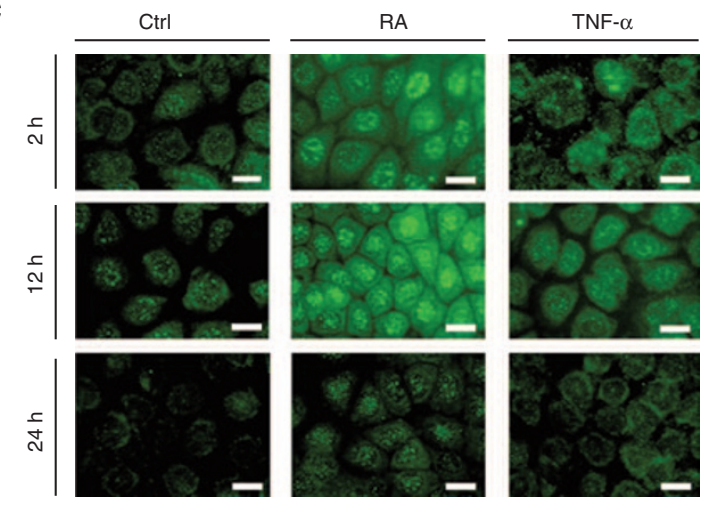

Figure 4. RA and RA+TNF- $\alpha$ strengthen the expression of Math 1 in cultured mMEECs. (a) Incubation of cells with RA for 12-24h increased the expression of the Math1 mRNA transcripts by RT-PCR. (b) FACS verified that RA, TNF- $\alpha$, and RA+TNF- $\alpha$ for $12 \mathrm{~h}$ increased Math 1-positive cell numbers $(n=2)$. (c) Immunohistochemistry further confirmed an increase of Math1-positive cells and translocation into the nuclei after treatment with RA and TNF- $\alpha$ in a time-dependent manner (within 2-12 h). It is noted that both RA and TNF- $\alpha$ had no effect on the Math 1 translocation to the nuclei at $24 \mathrm{~h}$. EGF $=20 \mathrm{ng} / \mathrm{ml}, \mathrm{TNF}-\alpha=20 \mathrm{ng} / \mathrm{ml}, \mathrm{RA}=1 \mu \mathrm{mol} / \mathrm{l}$. Bar $=5 \mu \mathrm{m}$. Ctrl, control; FACS, fluorescence-activated cell sorting; mMEEC, mouse middle ear epithelial cell; RA, retinoid acid; RT-PCR, reverse-transcription PCR; TNF$\alpha$, tumor necrosis factor- $\alpha$.

the expression of mucins or TFF3 in vivo, it is not sufficient for the differentiation of mucous cells in a cell culture system. Math1, TNF- $\alpha$, and RA synergistically promote mucous cell differentiation in vitro, suggesting that they are therapeutic targets for MCM in OM or asthma in the airway.

It is poorly understood how many signaling pathways are involved in the differentiation of mucous cells. The data collected from the current study indicate that the complex effects of Math $1+$ TNF- $\alpha+$ RA on mucous cell differentiation are blocked by several specific inhibitors such as SB203580, LY294002, AG1478, and SP60012. They suggest that TNF- $\alpha+R A+$ Math1synergized mucous cell differentiation is a result of the interactions between different pathways. Cross talk between cytokines and factors is essential for mucous cell differentiation. Further studies are warranted to clarify the specific signaling pathways for individual cytokines in order to design specific therapeutic interventions relevant to inflammatory cytokines.

\section{METHODS}

\section{Cell Cultures}

mMEECs were prepared in our laboratory as previously described (29). They were maintained in Ham's F-12K culture media (American Type Culture Collection, Manassas, VA) supplemented with $2 \mathrm{mmol} / \mathrm{l}$ L-glutamine and $10 \mathrm{ng} / \mathrm{ml}$ epidermal growth factor, $5 \mu \mathrm{l} / \mathrm{ml}$ insulintransferrin-sodium selenite (100x; Sigma-Aldrich, St Louis, MO) a

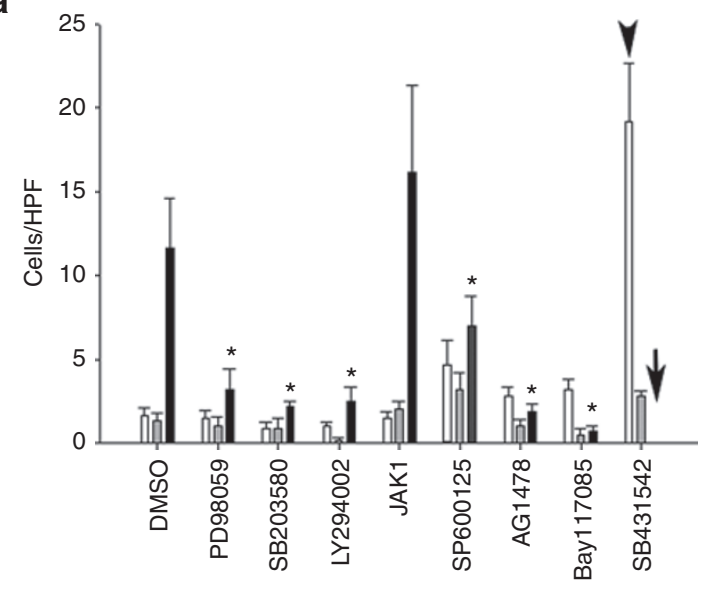

b

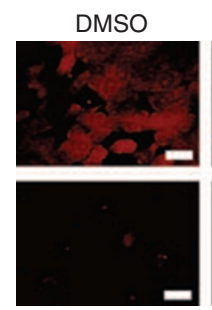

LY294002

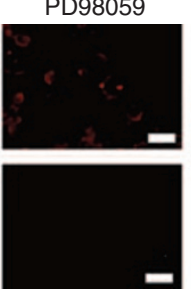

AG1478
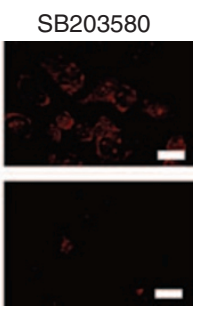

SP600125
Figure 5. Multiple signaling pathways are involved in mucous cell differentiation by TNF- $\alpha+$ RA+Math1. (a) All the inhibitors used in this study, except JAK1, significantly inhibited the mucous granule formation induced by TNF- $\alpha+$ RA+Math1 (white bar, TMath1; gray bar, RMath1; black bar, TRMath 1). JAK1 did not affect the mucous cell differentiation triggered by TNF- $\alpha+R A+$ Math1, whereas SB431542 increased the mucous cell differentiation triggered by TNF- $\alpha+$ Math 1 (arrowhead) but toxic to TNF- $\alpha+R A+$ Math1-treated cells (black arrow). (b) Immunohistochemistry demonstrated that PD98059, SB203580, LY294002, AG1478, and SP600125 inhibited the expression of TFF 3 in TNF- $\alpha+R A+$ Math1-treated cells. Bar $=5 \mu \mathrm{m} .{ }^{*} P<0.05(n=6)$. JAK1, Janus kinase $1 ; R A$, retinoid acid; RMath1, RA+Math1; TFF, trefoil factor; TMath1, TNF-a+Math1; TRMath1, TNF-a+RA+Math1; TNF- $\alpha$, tumor necrosis factor- $\alpha$.

solution, $2.7 \mathrm{~g} / \mathrm{l}$ glucose, $500 \mathrm{ng} / \mathrm{ml}$ hydrocortisone, $0.1 \mathrm{mmol} / \mathrm{l} \mathrm{non-}$ essential amino acids, $50 \mu \mathrm{g} / \mathrm{ml}$ streptomycin, 50 units $/ \mathrm{ml}$ penicillin, and $4 \%$ fetal bovine serum, hereafter referred to as full growth medium. Full growth medium change was made every $3-4 \mathrm{~d}$. During the experiment, epidermal growth factor in the above media was omitted when various factors were added.

\section{Regulation of Math 1 in mMEECs}

mMEECs were cultured on eight-well chamber slides or in T25 flasks. Cells were starved in F-12K culture medium for $24 \mathrm{~h}$, then incubated with, $20 \mathrm{ng} / \mathrm{ml}$ TNF- $\alpha, 10^{-9} \mathrm{~mol} / \mathrm{l} \mathrm{RA}$, or TNF- $\alpha+\mathrm{RA}$ for $12 \mathrm{~h}$ and harvested for the evaluation of Math1 expression.

\section{Transfection of Math 1 in the Middle Ear Mucosa of Mice}

Full-length Math1 complementary DNA (cDNA) was cloned into a protein-expressing vector (C2 pEGFP, i.e., ev; Clontech, San Diego, CA), as previously described (30). The Math1 cDNA sequence in ev in a sense manner was confirmed by sequencing and referred to as sense-Math 1 cDNA (hereinafter referred to as Math1). To study the role of Math1 in the differentiation of mucous cells, bilateral bullae of five mice were transfected with $10 \mu \mathrm{l}$ of Mathl or ev at $1.4 \mu \mathrm{g} / \mathrm{ml}$ in Opti-MEM (Invitrogen, Grand Island, NY) containing Lipofectin (Invitrogen) at $6 \mu \mathrm{g} / \mathrm{ml}$ via the tympanic membrane approach. Transfected animals were killed $7 \mathrm{~d}$ after Math 1 transfection for harvest of the bullae. The bullae were then fixed in 10\% formalin and routinely processed for histological sections. AB-PAS was used for the 


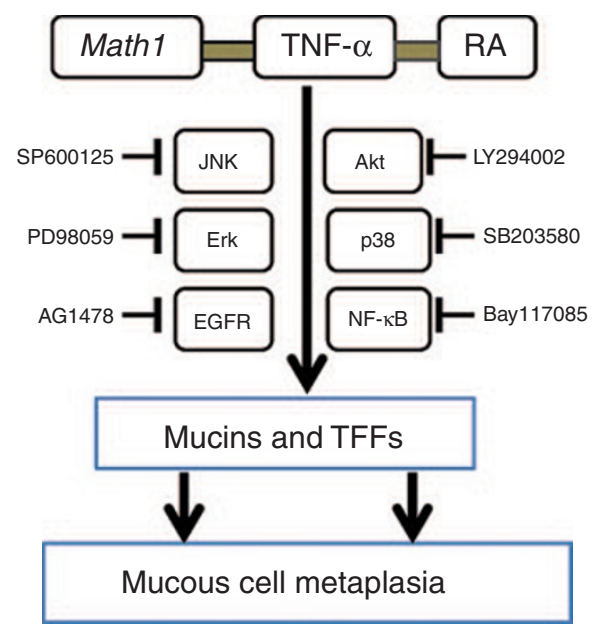

Figure 6. A flowchart summary of the signaling pathways involved in mucous cell metaplasia by TNF- $\alpha+R A+$ Math 1 in mMEECs. As assessed by AB-PAS and immunohistochemistry data (see Figure 5), the Erk, p38MAPK, Akt, EGFR, JNK, and NF-KB signaling pathways are involved in TNF$\alpha+R A+$ Math 1-induced mucous-like cells (AB-PAS positive). In other words, Math 1, TNF- $\alpha$, and RA may act through the above signaling pathways synergistically to increase the proliferation and differentiation of mucous cells in cultured mMEECs, and blockage of the above pathways may lead to therapeutic interventions of mucous cell metaplasia in the middle ear milieu. AB-PAS, Alcian blue-periodic acid Schiff; Akt, protein kinase B; EGFR, epidermal growth factor receptor; Erk, extracellular signal-regulated kinases; JNK, c-Jun N-terminal kinases; mMEEC, mouse middle ear epithelial cell; p38MAPK, p38 motogen-activated protein kinases; NF- $\kappa B$, nuclear factor kappa B; RA, retinoid acid; TNF- $\alpha$, tumor necrosis factor- $\alpha$.

identification of mucous cells. Mucous cell numbers were quantitatively analyzed by the previously described method (31). This animal study was performed in accordance with the animal use protocol and was approved by the institutional animal care and use committee at the University of Minnesota.

\section{Establishment of Math1 Stably Transfected mMEECs}

In our pilot study, cDNA transfection efficiency of mMEECs was low, and transient transfection was obviously insufficient for the determination of the effect of Math1 on cells. To overcome this problem, mMEECs were were stably transfected with Math1 and ev. Briefly, cells were cultured in a 12 -well plate to $70 \%$ confluence and transfected with s-Math1 and ev at $1.4 \mu \mathrm{g} / \mathrm{ml}$ for $16 \mathrm{~h}$ in Opti-MEM (serum-free; Invitrogen) containing $6 \mu \mathrm{g} / \mathrm{ml}$ of Lipofectin, cultured in full growth medium, incubated with $\mathrm{G} 418$ (400 $\mu \mathrm{g} / \mathrm{ml}$; Invitrogen) for $2 \mathrm{wk}$ for selection of successfully transfected cells. This procedure was repeated once. Cells persistently resistant to G418 for 3 mo were defined as stably transfected cells. To select cells highly positive for green fluorescent protein, the top $5 \%$ of green fluorescent protein-positive cells were sorted out by a cell sorter (FACSAria; BD Biosciences, Mountain View, CA) as described previously (32). Math $1 \mathrm{mRNA}$ and protein expression in these selected cell clones were routinely examined by RT-PCR, immunohistochemistry, and/ or FACS for verification of Math1 expression.

\section{Induction of Mucous Cell Differentiation in Math1 Stably Transfected Cells}

Math1 and ev stably transfected cells were cultured for $24 \mathrm{~h}$ in T-25 flasks or on eight-well chamber slides with a starting cell number at $\sim 2.5 \times 10^{4}$ cells per well in starvation media ( $2 \%$ serum without any growth factors). Cells were incubated with $20 \mathrm{ng} / \mathrm{ml}$ of TNF- $\alpha, 10^{-9}$ $\mathrm{mol} / \mathrm{l}$ of RA, or TNF- $\alpha+\mathrm{RA}$ for $2 \mathrm{wk}$ in full growth medium (media and factors were supplied every $2 \mathrm{~d}$ ) and then starvation media for 2 $\mathrm{d}$. Cells were then harvested for the evaluation of mucous cell differentiation by AB-PAS, immunohistochemistry, and FACS.
Inhibition of Mucous Cell Differentiation With Specific Inhibitors To study which signaling pathways are involved in mucous cell differentiation, Math 1 and ev stably transfected cells were preincubated with pathway inhibitors $(25 \mu \mathrm{mol} / \mathrm{l}$ PD98059 for the extracellular signal-regulated kinases (Erk) pathway, $20 \mu \mathrm{mol} / \mathrm{l} \mathrm{LY} 294002$ for the Akt pathway, $10 \mu \mathrm{mol} / \mathrm{l}$ AG1478 for the EGFR pathway, $1 \mu \mathrm{mol} / \mathrm{l} \mathrm{JAK} 1$ inhibitor I for JAKs, $20 \mu \mathrm{mol} / \mathrm{l}$ BAY117085 for NF-kB, and $10 \mu \mathrm{mol} / \mathrm{l}$ SB431542 for TGFb RI kinase all from Calbiochem-Novabiochem, San Diego, CA; $15 \mu \mathrm{mol} / 1 \mathrm{SB} 203580$ for the p38 mitogen-activated protein kinases (MAPK) pathway and $20 \mu \mathrm{mol} / 1$ SP600125 for the c-Jun N-terminal kinases (JNK) pathway, from Sigma-Aldrich) for $2 \mathrm{~h}$ and incubated with TNF- $\alpha$, RA, or TNF- $\alpha+$ RA for $14 \mathrm{~d}$ in the presence of the above inhibitors, followed by the above starvation media for $2 \mathrm{~d}$ without TNF- $\alpha$, RA, and TNF- $\alpha+$ RA but with inhibitors. Cells were harvested for the evaluation of mucous cell differentiation by AB-PAS, immunohistochemistry, and FACS.

\section{AB-PAS Stain}

Cells on chamber slides were fixed with $100 \%$ ethanol for $6 \mathrm{~min}$ at room temperature and incubated with $1 \% \mathrm{AB}$ for $30 \mathrm{~min}, 0.5 \%$ PAS reagent for $10 \mathrm{~min}$, then sulfurous acid for $2 \mathrm{~min}$. Slides were washed in tap water and examined under a light microscope for the identification of positive mucous granules. Cells with blue and purple colors were defined as mucous cells. Mucous cell numbers from four to six areas on each chamber were counted. Quantitative data are presented as mean \pm SE. Total cell numbers were determined by 4,6-diamidino2-phenylindole stain simultaneously, and the percentage of AB-PASpositive cells against total cells was calculated. Final mucous cells are presented as the percentage of total cell numbers.

\section{Immunohistochemistry}

Cells on Lab-Tec chamber slides (Nalge Nunc International, Naperville, IL) were fixed in $100 \%$ ethanol and incubated with mucous cell marker antibodies: anti-TFF3 (1:50; Calbiochem) or antiMath1 (1:100; Abcam, Cambridge, MA) at $4{ }^{\circ} \mathrm{C}$ overnight, washed with phosphate-buffered saline (PBS), incubated with fluorescein isothiocyanate- or tetramethylrhodamine isothiocyanate-conjugated secondary antibodies (Zymed, Santa Cruz, CA) for $60 \mathrm{~min}$ at room temperature, once again washed with $\mathrm{PBS}$, and examined under a fluorescence or a confocal microscope. Nonspecific IgG was used as an immunohistochemistry-negative control.

\section{Fluorescence-Activated Cell Sorting}

Cells were incubated with $0.3 \%$ saponin in PBS for $5 \mathrm{~min}$, incubated with anti-Muc2 (1:100, Zymed, CA) anti-TFF3 (1:50) or anti-Math1 (1:50) for $30 \mathrm{~min}$ on ice, washed with $0.3 \%$ saponin in PBS twice, incubated with tetramethylrhodamine isothiocyanate-conjugated secondary antibody for 30 min on ice, again washed with $0.3 \%$ saponin in PBS twice, and analyzed on a BD FACSCalibur flow cytometer (BD Biosciences). Cells incubated with nonspecific IgG (Zymed products), followed by tetramethylrhodamine isothiocyanate-conjugated secondary antibodies, served as antibody controls. Data were analyzed with CellQuest Pro (BD Sciences) and FlowJO (version 7.1; Tree Star, Ashland, OR) for presentation. Experiments were run in duplicate or triplicate. Results are presented as the percentage of positive cells over 3,000 cells per sample after subtraction of cells with nonspecific IgG background.

\section{RT-PCR}

Total RNA was isolated from the above harvested cells using an RNA Miniprep Kit (Stratagene, La Jolla, CA). Residual genomic DNA in total RNA samples was digested with DNases according to the manufacturer's instruction. Specific primers for Math1, TFF3, and glyceraldehyde 3-phosphate dehydrogenase were as follows: Math1 primers: 5'-AGATCTACATCAACGCTCTGTC-3'/5'-ACTGGCCTCATC AGAGTCACTG-3' $\left(58.5^{\circ} \mathrm{C}, 452 \mathrm{bp}, 30\right.$ cycles); and glyceraldehyde 3-phosphate dehydrogenase primers: $5^{\prime}$-AACGGGAAGCCCATCA CC-3'/5'-CAGCCTTGGCAGCACCAG-3' (61 ${ }^{\circ} \mathrm{C}$, $441 \mathrm{bp}, 20$ cycles). The specificity of these primers was assessed by Basic Local Alignment Search Tool using the National Center of Biologic Information website (http://www.ncbi.nlm.nih.gov). RT-PCR was performed as 
described previously $(33,34)$. PCR products were analyzed on a $2 \%$ agarose gel for the evaluation of band sizes and routinely purified for sequence verification. RNA samples omitting reverse-transcription enzyme served as controls.

\section{Microarrays}

Affymetrix microarrays (Affymetrix, Santa Clara, CA) were performed using the above total RNA as previously described (35). Briefly, cDNA was prepared from $20 \mu$ g total RNA using a T7-dT primer. Complementary RNA was synthesized from cDNA and biotinylated using the BioArray High Yield RNA Transcript Labeling Kit (Enzo Diagnostics, Farmingdale, NY) and hybridized with the Rat U34 array (Affymetrix). The microarray data were analyzed as previously described (35).

\section{SUPPLEMENTARY MATERIAL}

Supplementary material is linked to the online version of the paper at http:// www.nature.com/pr

\section{STATEMENT OF FINANCIAL SUPPORT}

This study was supported in part by National Institutes of Health (Bethesda, MD) grant R01 DC008165, supplement grant 00010055 from the National Institute of Deafness and Other Communication Disorders, the National Organization for Hearing Research, and the 5M Lions International Hearing Foundation.

Disclosure: The authors declared no conflict of interest.

\section{REFERENCES}

1. Kawano H, Paparella MM, Ho SB, et al. Identification of MUC5B mucin gene in human middle ear with chronic otitis media. Laryngoscope 2000;110:668-73.

2. Lin J, Tsuboi Y, Rimell F, et al. Expression of mucins in mucoid otitis media. J Assoc Res Otolaryngol 2003;4:384-93.

3. Tos M, Bak-Pedersen K. Secretory otitis. Histopathology and goblet-cell density in the Eustachian tube and middle ear in children. J Laryngol Otol 1976;90:475-85.

4. Tos M, Bak-Pedersen K. Goblet cell population in the pathological middle ear and eustachian tube of children and adults. Ann Otol Rhinol Laryngol 1977;86(2 Pt 1):209-18.

5. Rinaldo A, Ferlito A. The pathology and clinical features of "glue ear": a review. Eur Arch Otorhinolaryngol 2000;257:300-3.

6. Tos M, Caye-Thomasen P. Mucous glands in the middle ear - what is known and what is not. ORL J Otorhinolaryngol Relat Spec 2002;64:86-94.

7. Alper CM, Bluestone CD, Buchman C, et al. Recent advances in otitis media. 3. Middle ear physiology and pathophysiology. Ann Otol Rhinol Laryngol Suppl 2002;188:26-35.

8. Lin J, Tsuprun V, Kawano H, et al. Characterization of mucins in human middle ear and Eustachian tube. Am J Physiol Lung Cell Mol Physiol 2001;280:L1157-67.

9. Wiede A, Jagla W, Welte T, Köhnlein T, Busk H, Hoffmann W. Localization of TFF3, a new mucus-associated peptide of the human respiratory tract. Am J Respir Crit Care Med 1999;159(4 Pt 1):1330-5.

10. Kawano H, Haruta A, Tsuboi Y, et al. Induction of mucous cell metaplasia by tumor necrosis factor alpha in rat middle ear: the pathological basis for mucin hyperproduction in mucoid otitis media. Ann Otol Rhinol Laryngol 2002;111(5 Pt 1):415-22.

11. Yang Q, Bermingham NA, Finegold MJ, Zoghbi HY. Requirement of Math1 for secretory cell lineage commitment in the mouse intestine. Science 2001;294:2155-8.

12. Lin J, Haruta A, Kawano $\mathrm{H}$, et al. Induction of mucin gene expression in middle ear of rats by tumor necrosis factor-alpha: potential cause for mucoid otitis media. J Infect Dis 2000;182:882-7.

13. Lin J, Kim Y, Juhn SK. Increase of mucous glycoprotein secretion by tumor necrosis factor alpha via a protein kinase C-dependent mechanism in cultured chinchilla middle ear epithelial cells. Ann Otol Rhinol Laryngol 1998;107:213-9.

14. Levine SJ, Larivée P, Logun C, Angus CW, Ognibene FP, Shelhamer JH. Tumor necrosis factor-alpha induces mucin hypersecretion and MUC-2 gene expression by human airway epithelial cells. Am J Respir Cell Mol Biol 1995;12:196-204.
15. Dabbagh K, Takeyama K, Lee HM, Ueki IF, Lausier JA, Nadel JA. IL-4 induces mucin gene expression and goblet cell metaplasia in vitro and in vivo. J Immunol 1999;162:6233-7.

16. Lee CG, Homer RJ, Cohn L, et al. Transgenic overexpression of interleukin (IL)-10 in the lung causes mucus metaplasia, tissue inflammation, and airway remodeling via IL-13-dependent and -independent pathways. J Biol Chem 2002;277:35466-74.

17. Smirnova MG, Birchall JP, Pearson JP. In vitro study of IL-8 and goblet cells: possible role of IL-8 in the aetiology of otitis media with effusion. Acta Otolaryngol 2002;122:146-52.

18. Longphre M, Li D, Gallup M, et al. Allergen-induced IL-9 directly stimulates mucin transcription in respiratory epithelial cells. J Clin Invest 1999;104:1375-82.

19. Laoukili J, Perret E, Willems T, et al. IL-13 alters mucociliary differentiation and ciliary beating of human respiratory epithelial cells. J Clin Invest 2001;108:1817-24.

20. Kondo M, Tamaoki J, Takeyama K, Nakata J, Nagai A. Interleukin-13 induces goblet cell differentiation in primary cell culture from Guinea pig tracheal epithelium. Am J Respir Cell Mol Biol 2002;27:536-41.

21. Whittaker L, Niu N, Temann UA, et al. Interleukin-13 mediates a fundamental pathway for airway epithelial mucus induced by CD4 T cells and interleukin-9. Am J Respir Cell Mol Biol 2002;27:593-602.

22. Leow CC, Romero MS, Ross S, Polakis P, Gao WQ. Hath1, down-regulated in colon adenocarcinomas, inhibits proliferation and tumorigenesis of colon cancer cells. Cancer Res 2004;64:6050-7.

23. Sekine A, Akiyama Y, Yanagihara K, Yuasa Y. Hath1 up-regulates gastric mucin gene expression in gastric cells. Biochem Biophys Res Commun 2006;344:1166-71.

24. Gray T, Koo JS, Nettesheim P. Regulation of mucous differentiation and mucin gene expression in the tracheobronchial epithelium. Toxicology 2001;160:35-46.

25. Durual S, Blanchard C, Estienne M, et al. Expression of human TFF3 in relation to growth of HT-29 cell subpopulations: involvement of PI3-K but not STAT6. Differentiation 2005;73:36-44.

26. Taupin D, Wu DC, Jeon WK, Devaney K, Wang TC, Podolsky DK. The trefoil gene family are coordinately expressed immediate-early genes: EGF receptor- and MAP kinase-dependent interregulation. J Clin Invest 1999;103:R31-8.

27. Manna B, Ashbaugh P, Bhattacharyya SN. Retinoic acid-regulated cellular differentiation and mucin gene expression in isolated rabbit tracheal-epithelial cells in culture. Inflammation 1995;19:489-502.

28. Koo JS, Yoon JH, Gray T, Norford D, Jetten AM, Nettesheim P. Restoration of the mucous phenotype by retinoic acid in retinoid-deficient human bronchial cell cultures: changes in mucin gene expression. Am J Respir Cell Mol Biol 1999;20:43-52.

29. Tsuchiya K, Kim Y, Ondrey FG, Lin J. Characterization of a temperature-sensitive mouse middle ear epithelial cell line. Acta Otolaryngol 2005; 125:823-9.

30. Hu X, Huang J, Feng L, Fukudome S, Hamajima Y, Lin J. Sonic hedgehog $(\mathrm{SHH})$ promotes the differentiation of mouse cochlear neural progenitors via the Math1-Brn3.1 signaling pathway in vitro. J Neurosci Res 2010;88:927-35

31. Tsuboi Y, Kim Y, Giebink GS, et al. Induction of mucous cell metaplasia in the middle ear of rats using a three-step method: an improved model for otitis media with mucoid effusion. Acta Otolaryngol 2002;122: 153-60.

32. Perez-Pujol S, Marker PH, Key NS. Platelet microparticles are heterogeneous and highly dependent on the activation mechanism: studies using a new digital flow cytometer. Cytometry A 2007;71:38-45.

33. Ozeki M, Duan L, Hamajima Y, Obritch W, Edson-Herzovi D, Lin J. Establishment and characterization of rat progenitor hair cell lines. Hear Res 2003;179:43-52.

34. Ozeki M, Hamajima Y, Feng L, Ondrey FG, Schlentz E, Lin J. Id1 induces the proliferation of cochlear sensory epithelial cells via the nuclear factorkappaB/cyclin D1 pathway in vitro. J Neurosci Res 2007;85:515-24.

35. Lin J, Tsuboi Y, Pan W, Giebink GS, Adams GL, Kim Y. Analysis by cDNA microarrays of altered gene expression in middle ears of rats following pneumococcal infection. Int J Pediatr Otorhinolaryngol 2002;65:203-11. 